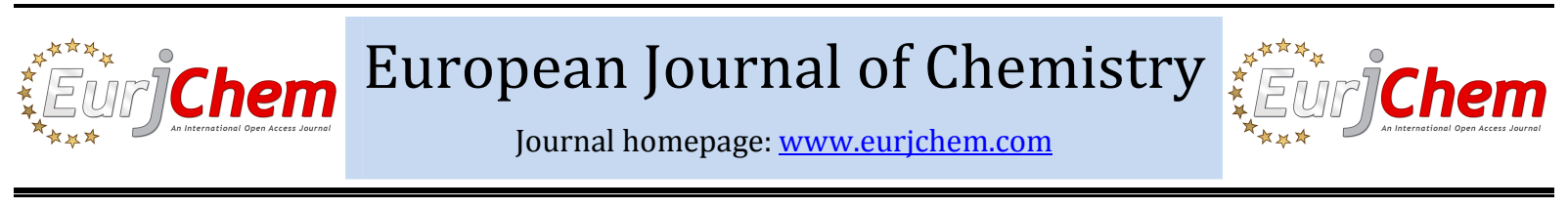

\title{
Study of the adsorption of Co(II) on the chitosan-hydroxyapatite
}

\author{
Zhiguang Ma*, Mengchao Liu, Jianghong Li, Yinan Song and Suwen Liu \\ College of Chemistry and Environmental Science, Key Laboratory of Medicinal Chemistry and Molecular Diagnosis, Hebei University, Baoding 071002, China \\ *Corresponding author at: College of Chemistry and Environmental Science, Key Laboratory of Medicinal Chemistry and Molecular Diagnosis, Hebei University, \\ Baoding 071002, China. \\ Tel.: +86.0312.5079359. Fax: +86.0312.5079525. E-mail address: hxymzg@163.com (Z. Ma).
}

\section{ARTICLE INFORMATION}

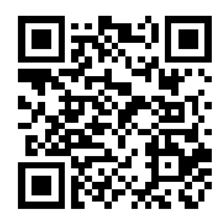

DOI: 10.5155 /eurjchem.5.2.209-213.948

Received: 18 October 2013

Received in revised form: 13 December 2013

Accepted: 16 December 2013

Online: 30 June 2014

\section{KEYWORDS}

Cobalt

Kinetics

Chitosan

Adsorption

Hydroxyapatite

Thermodynamics

\section{Introduction}

In the earth's crust, the cobalt content is very high. Cobalt is very useful cemented carbide industry, ceramics, electroplating industry, and so on. Cobalt ion is toxic. Accumulated cobalt ion in human body can have serious effect on human health, resulting in dysfunctions of heart, lung, liver, spleen, stomach and other organs, and even causing cancers [1-3]. Therefore, many types of adsorption materials have been developed to remove $\mathrm{Co}^{2+}$ from aqueous solution. These materials include vermiculite [4], zeolite [5], sepiolite [6], kaolinite [7], and Chitosan-aluminium oxide [8]. In addition, the Chitosanaluminium oxide material was also used to remove $\mathrm{Zn}^{2+}$ from aqueous solution [9].

Chitosan (CS) can be obtained through deacetylation of the natural polymer chitin which widely exists in nature. There is a large number of hydroxyl and amino groups in the chitosan chain, which can be used as adsorbent for the heavy metal ions in wastewater [10-14]. However, as an adsorbent, the mechanical strength of chitosan is not very good, and its dissolution in the acidic solution can also have negative effect on its performance. Hydroxyapatite (HA) has unique chemical structure and is widely used to adsorb metal ions [15]. So, chitosan-hydroxyapatite (CS/HA) composite material is expected to be able to overcome the shortcoming of chitosan. For example, a CS/HA composite material has been prepared by Xie et al. using chitosan, lime nitrate tetra-hydrate, and potassium di-hydrogen phosphate [16].

In this manuscript, we focus on a better understanding of the fundamental aspects of the adsorption of heavy metal such as cobalt onto CS/HA composite material and present a thorough kinetic and thermodynamic investigation of the adsorption process. We hope our studies can provide valuable insights for a better design of chitosan-inorganic composite materials.

\section{Experimental}

\subsection{Materials}

Chitosan $(>90 \%)$ is purchased from Zhejiang Golden-Shell Biochemical Co., Ltd., China. Cobalt nitrate $\left(\mathrm{Co}\left(\mathrm{NO}_{3}\right)_{2} \cdot 6 \mathrm{H}_{2} \mathrm{O}\right)$ $(>99.5 \%)$ is purchased by Sinopharm Chemical Reagent Co., Ltd. China. Acetic acid, calcium nitrate $\left(\mathrm{Ca}\left(\mathrm{NO}_{3}\right)_{2} \cdot 4 \mathrm{H}_{2} \mathrm{O}\right)$, potassium dihydrogen phosphate $\left(\mathrm{KH}_{2} \mathrm{PO}_{4}\right)$, hydrochloric acid $(\mathrm{HCl})$, and sodium hydroxide $(\mathrm{NaOH})$ are of analytical reagent grade and were purchased from Tianjin Chemical Reagent Co. Ltd, China. All solutions are prepared in deionized water. Hydrochloric acid and $\mathrm{NaOH}$ are used to adjust the $\mathrm{pH}$.

\subsection{Preparation of $\mathrm{CS} / \mathrm{HA}$}


CS/HA composite material is prepared according to the procedure described in previous study [16]. Briefly, $100 \mathrm{~g}$ of chitosan is added into $75 \mathrm{~mL}$ of $2 \%$ acetic acid, and then $1.25 \mathrm{~g}$ of $\mathrm{Ca}\left(\mathrm{NO}_{3}\right)_{2} \cdot 4 \mathrm{H}_{2} \mathrm{O}$ and $0.43 \mathrm{~g}$ of $\mathrm{KH}_{2} \mathrm{PO}_{4}$ were added into the solution. The combination of $\mathrm{Ca}\left(\mathrm{NO}_{3}\right)_{2} \cdot 4 \mathrm{H}_{2} \mathrm{O}$ and $\mathrm{KH}_{2} \mathrm{PO}_{4}$ results in the formation of hydroxyapatite (HA) in situ. The relative ratio of CS over HA is kept at 10:1. During the preparation, about 3-8\% $\mathrm{NaOH}$ solution should be added to the mixture under stirring to give an uniform and transparent solution. After the reaction is completed, it is allowed to stand for $12 \mathrm{~h}$. The crude product is washed until the $\mathrm{pH}$ is neutral, and then dried at $338 \mathrm{~K}$ in the oven. The final product is then ground to 80 mesh.

\subsection{Methods}

All batch adsorption experiments are conducted in $50 \mathrm{~mL}$ flask. A mixture of $0.5 \mathrm{~g}$ of adsorbents and $25 \mathrm{~mL}$ of $\mathrm{Co}\left(\mathrm{NO}_{3}\right)_{2}$ solution of different initial concentration is added into the flask. The hydrochloric acid solution and sodium hydroxide solution are used to adjust the $\mathrm{pH}$. The flask is shaken in a thermostated shaker at $130 \mathrm{rpm}$ under different temperatures. After adsorption, the absorbent is filtered and the concentration of the $\mathrm{Co}^{2+}$ in the filtrate is determined by UV-Vis spectroscopy using $512 \mathrm{~nm}$. Adsorption capacity is calculated according to Equation 1.

$\mathrm{Q}=\left(\mathrm{C}_{0}-\mathrm{C}\right) \times \mathrm{V} / \mathrm{m}$

where $\mathrm{Q}(\mathrm{mmol} / \mathrm{g})$ is adsorption capacity, $\mathrm{C}_{0}(\mathrm{~mol} / \mathrm{L})$ and $\mathrm{C}$ $(\mathrm{mol} / \mathrm{L})$ are the initial concentration and the final concentration of $\mathrm{Co}^{2+}, \mathrm{V}(\mathrm{mL})$ is the solution volume, and $\mathrm{m}(\mathrm{g})$ is the adsorbent mass.

\section{Results and discussion}

\subsection{Influence of adsorption time on the adsorption capacity}

We first determined the optimum adsorption time. We studied the influence of adsorption time on the adsorption capacity at $298.2 \mathrm{~K}$ with an initial $\mathrm{Co}^{2+}$ concentration of 0.1000 $\mathrm{mol} / \mathrm{L}$. As we can see in Figure 1, the adsorption capacity reaches a plateau after $480 \mathrm{~min}$ adsorption. This adsorption time is then used as the optimum adsorption time in the following experiments.

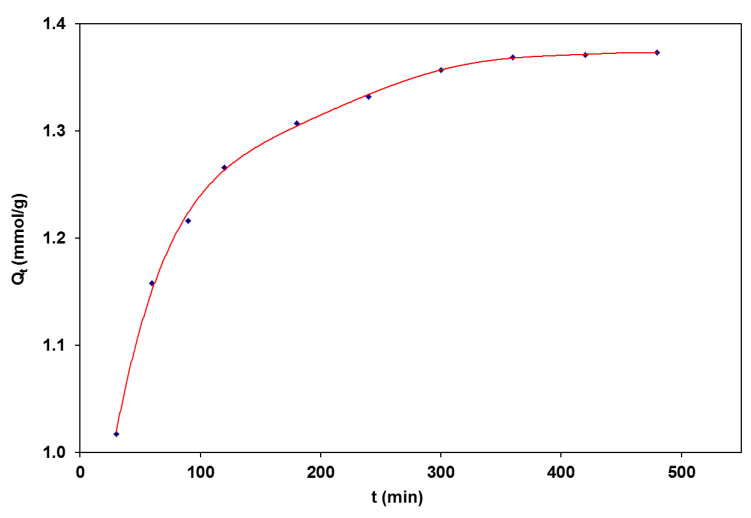

Figure 1. The influence of time on the adsorption capacity of $\mathrm{Co}^{2+}$.

\subsection{Influence of temperature on the adsorption capacity}

We then studied the influence of temperature on adsorption capacity. At five different temperatures of 293.2, $298.2,308.2,318.2$, and $328.2 \mathrm{~K}$, the influence of adsorption temperature is investigated with the $\mathrm{Co}^{2+}$ concentration of $0.1000 \mathrm{~mol} / \mathrm{L}$. The results illustrate in Figure 2 shows that with the increase of temperature, the adsorption capacity increases rapidly. Based on this result, we can infer that the adsorption is an endothermic process.

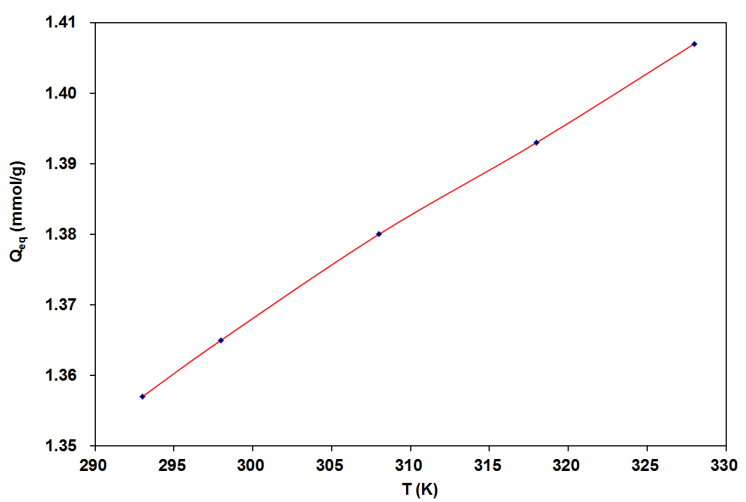

Figure 2. The influence of temperature on the adsorption capacity of $\mathrm{Co}^{2+}$.

\subsection{Influence of initial $\mathrm{Co}^{2+}$ concentration on the adsorption capacity}

The influence of initial concentration on adsorption capacity is studied at $298.2 \mathrm{~K}$ with the adsorption time of 480 minute. As shown in Figure 3, it is found that the adsorption capacity varies with the initial concentration of $\mathrm{Co}^{2+}$. The results illustrate that the adsorption capacity of $\mathrm{Co}^{2+}$ on the $\mathrm{CS} / \mathrm{HA}$ increases with the initial concentration increasing. The adsorption capacity grows rapidly when initial concentration is smaller than $0.2500 \mathrm{~mol} / \mathrm{L}$, and then trends to slow down when the initial concentration is $0.2500 \mathrm{~mol} / \mathrm{L}$ capacity. This may be caused by an increase in the driving force of the concentration gradient with the increase in the initial concentration [17].

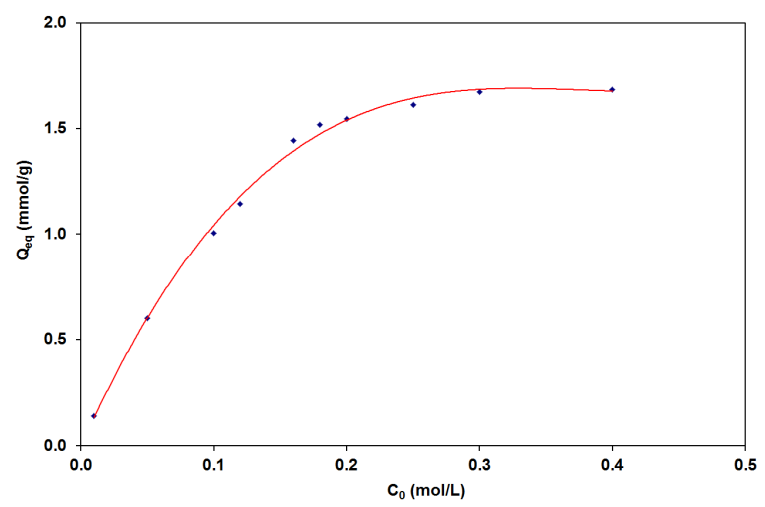

Figure 3. The influence of the initial concentration on the adsorption capacity of $\mathrm{Co}^{2+}$.

\subsection{Influence of $\mathrm{pH}$ on the adsorption capacity}

As is well known, the $\mathrm{pH}$ of solution is an important parameter affecting the adsorption of metal ions on the adsorbents as it not only influences metal speciation in solution, but also influences the surface properties of the adsorbents due to the dissociation of functional groups and the variation of surface charges under different $\mathrm{pHs}$ [18]. In order to evaluate the influence of $\mathrm{pH}$ on the adsorption of $\mathrm{Co}^{2+}$, the effect of $\mathrm{pH}$ on the adsorption capacity is studied. The experiment in conducted in the $\mathrm{pH}$ range from 2.2 to 6.8 , and the influence of $\mathrm{pH}$ on the adsorption capacity is thus determined. Results in Figure 4 illustrate that $\mathrm{pH}$ has little effect on the adsorption capacity when $\mathrm{pH}$ increases from 2.2 to 4.6 and then reaches a plateau at $\mathrm{pH}=6.8$. 
Table 1. Fitting results of the pseudo-second-order equation

\begin{tabular}{llll} 
T (K) & Fitting equation & $\mathbf{Q}_{\text {eq }}(\mathbf{m m o l} / \mathbf{g})$ & $\mathbf{k}(\mathrm{g} / \mathbf{m m o l} \cdot \mathbf{m i n})$ \\
\hline 293 & $\mathrm{t} / \mathrm{Q}_{\mathrm{t}}=0.7114 \mathrm{t}+10.66$ & 1.406 & 0.04747 \\
298 & $\mathrm{t} / \mathrm{Q}_{\mathrm{t}}=0.7071 \mathrm{t}+9.590$ & 1.412 & 0.05409 \\
308 & $\mathrm{t} / \mathrm{Q}_{\mathrm{t}}=0.7051 \mathrm{t}+8.162$ & 1.418 & 0.06227 \\
318 & $\mathrm{t} / \mathrm{Q}_{\mathrm{t}}=0.7035 \mathrm{t}+6.553$ & 1.434 & 0.06793 \\
328 & $\mathrm{t} / \mathrm{Q}_{\mathrm{t}}=0.6969 \mathrm{t}+5.587$ & 1.454 & 0.9999 \\
\hline
\end{tabular}

In addition, at $\mathrm{pH}=6.8$ the solution becomes turbid and some precipitates become visible. At low $\mathrm{pH}$, more protons will be available to protonate the amine groups in chitosan [19], thus reducing the number of binding sites for the adsorption of $\mathrm{Co}^{2+}$. This is why we observe a low adsorption capacity at low $\mathrm{pH}$. So, we can conclude that the optimum $\mathrm{pH}$ for $\mathrm{Co}^{2+}$ adsorption is between 5 and 7. In a previous study, the presence of cobalt ionic speciation was investigated and the results showed that cobalt is present in the aqueous solution mainly in the form of $\mathrm{Co}^{2+}$ up to $\mathrm{pH}=8$. This means that in the initial $\mathrm{pH}$ range of 4-8, cobalt ion is adsorbed on the absorbent through an ion exchange process with hydroxyapatite [20].

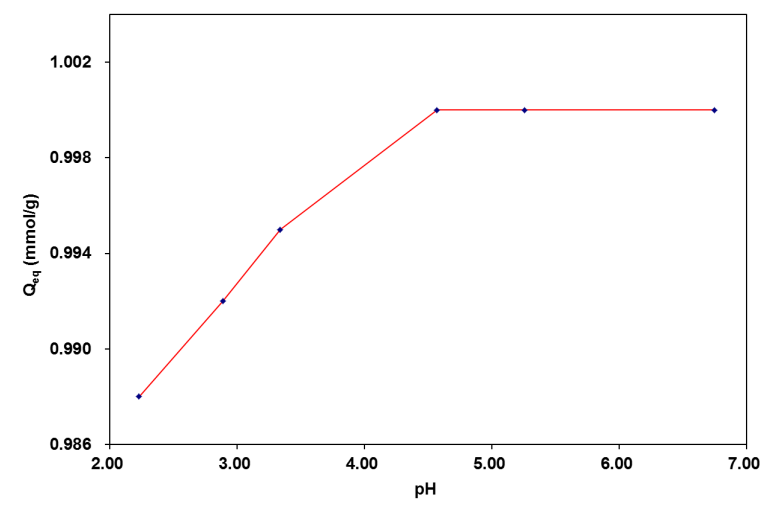

Figure 4. The influence of $\mathrm{pH}$ on adsorption capacity of $\mathrm{Co}^{2+}$.

\subsection{Kinetic studies on the adsorption of $\mathrm{Co}^{2+}$ on the $\mathrm{CS} / \mathrm{HA}$}

The adsorption kinetic curves of the $0.1000 \mathrm{~mol} / \mathrm{L} \mathrm{Co}^{2+}$ onto the CS/HA composite material at different temperatures are studied. At the early stage, the adsorption rate is fast, and then decreases with time. After about 420 minutes, the adsorption reaches equilibrium, as shown in Figure 5. At the beginning, the adsorption of $\mathrm{Co}^{2+}$ mainly occurs on the external surface of CS/HA and the adsorption rate thus increases rapidly. In the second stage, as the adsorbed cobalt ions diffuses inward into the CS/HA through the micropore, the resistance of diffusion increases with adsorption procedure. Absorption rate is mainly controlled by diffusion at this stage, so the rate of adsorption becomes small. At the final stage, the adsorption mainly occurs on the inner surface of adsorbent and the adsorption reaches equilibrium. So, this adsorption procedure is generally consistent with a three-step adsorption behavior which is usually observed from porous adsorbents $[21,22]$.

Pseudo-second-order kinetics model is based on the assumption of that: the rate of absorption is determined by the square of the number of vacancies [23]. The formula is:

$d Q_{t} / d t=k\left(Q_{e q}-Q_{t}\right)^{2}$

Integration of the Equation 2 under boundary conditions leads to Equation 3.

$\mathrm{t} / \mathrm{Q}_{\mathrm{t}}=\mathrm{t} / \mathrm{Q}_{\mathrm{eq}}+1 / \mathrm{kQ}_{\mathrm{eq}}{ }^{2}$ where $Q_{t}(\mathrm{mmol} / \mathrm{g})$ is the absorption capacity at any time; and $\mathrm{Q}_{\text {eq }}(\mathrm{mmol} / \mathrm{g}$ ) is the absorption capacity at equilibrium; $\mathrm{k}$ ( $\mathrm{g} / \mathrm{mmol} . \mathrm{min})$ is the adsorption rate constant.

If adsorption procedure conforms to the pseudo-secondorder equation, $t / Q_{t}$ and $t$ could have a linear relationship. Indeed, fitting the data in Table 1 shows that the pseudosecond-order kinetic model has a good correlation coefficient $\left(r^{2}=0.9999\right)$, indicating that the kinetic model fits well with the experimental data. The pseudo-second-order model supports that the rate-limiting step may be sorption involving valency forces through sharing or exchange of electrons between the $\mathrm{NH}_{2}$ groups in chitosan and $\mathrm{Co}^{2+}[24,25]$.

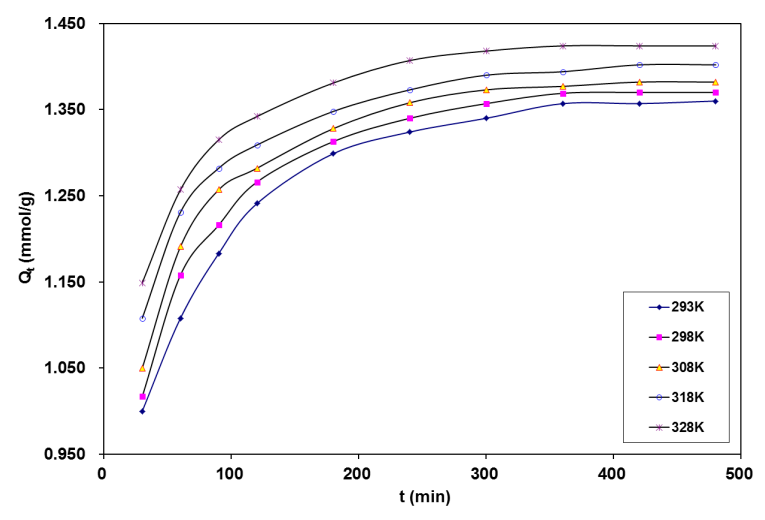

Figure 5. Adsorption kinetic curves at different temperatures.

Temperature study (Figure 6) shows a $r^{2}$ value of 0.99 . This indicates that the relationship between temperature and the rate of absorption obeyes the Arrhenius equation:

$\operatorname{Ln} \mathrm{k}=-\mathrm{E}_{\mathrm{a}} / \mathrm{RT}+\ln \mathrm{A}$

The temperature has significant effects on the rate constant $\mathrm{k}$. According to the Arrhenius equation, the obtained $E_{\mathrm{a}}$ is 10.73 $\mathrm{kJ} / \mathrm{mol}$.

\subsection{Thermodynamic studies on the adsorption of Co(II) on the $C S / H A$}

The adsorption thermodynamic curve of $\mathrm{Co}^{2+}$ concentrate on the CS/HA at different temperatures is detected using the absorption time of 480 minute. Results illustrate that the adsorption capacity of $\mathrm{Co}^{2+}$ on the CS/HA increases with the increase of the initial concentration of $\mathrm{Co}^{2+}$, and then it reaches a maximum value (Figure 7). This is due to that the amount of $\mathrm{CS} / \mathrm{HA}$ is at a fixed value and thus the number of adsorption sites is at a fixed value too [26]. At the beginning of the adsorption, the CS/HA could provide enough sites, thus the adsorption capacity of CS/HA is high; however, the active sites become insufficient when the initial concentration of $\mathrm{Co}^{2+}$ is high and the adsorption sites could be saturated under such situation.

The expression of the Langmuir adsorption model [27] is listed as below.

$\mathrm{C}_{\text {eq }} / \mathrm{Q}_{\mathrm{eq}}=\mathrm{C}_{\mathrm{eq}} / \mathrm{Q}_{\mathrm{m}}+1 / \mathrm{K}_{\mathrm{L}} \mathrm{Q}_{\mathrm{m}}$ 
Table 2. Parameters and equations for Langmuir adsorption model at five different temperatures

\begin{tabular}{|c|c|c|c|c|}
\hline $\mathrm{T}(\mathrm{K})$ & Langmuir equation & $\mathrm{Q}_{\mathrm{m}}(\mathrm{mmol} / \mathrm{g})$ & $\mathrm{K}_{\mathrm{L}}(\mathrm{L} / \mathrm{mmol})$ & $r^{2}$ \\
\hline 293 & $\mathrm{C}_{\mathrm{eq}} / \mathrm{Q}_{\mathrm{eq}}=0.5063 \mathrm{C}_{\mathrm{eq}}+35.55$ & 1.975 & 0.01424 & 0.9955 \\
\hline 298 & $C_{\text {eq }} / Q_{e q}=0.4940 C_{\text {eq }}+31.52$ & 2.024 & 0.01567 & 0.9958 \\
\hline 308 & $C_{\text {eq }} / Q_{e q}=0.4910 C_{e q}+25.86$ & 2.037 & 0.01899 & 0.9972 \\
\hline 318 & $C_{\text {eq }} / Q_{\text {eq }}=0.4892 C_{\text {eq }}+19.43$ & 2.044 & 0.02517 & 0.9968 \\
\hline 328 & $\mathrm{C}_{\mathrm{eq}} / \mathrm{Q}_{\mathrm{eq}}=0.4870 \mathrm{C}_{\mathrm{eq}}+16.02$ & 2.053 & 0.03040 & 0.9978 \\
\hline
\end{tabular}

Table 3. Thermodynamic parameters at different temperatures

\begin{tabular}{|c|c|c|c|c|}
\hline $\mathrm{T}(\mathrm{K})$ & $\Delta G^{\theta}(\mathrm{kJ} / \mathrm{mol})$ & $\Delta H^{\theta}(\mathrm{kJ} / \mathrm{mol})$ & $\Delta S^{\ominus}(\mathrm{J} / \mathrm{mol} \cdot \mathrm{K})$ & $r^{2}$ \\
\hline $293.2 \mathrm{~K}$ & -6.376 & & & \\
\hline $298.2 \mathrm{~K}$ & -6.793 & & & \\
\hline $308.2 \mathrm{~K}$ & -7.628 & 18.09 & 83.50 & 0.9888 \\
\hline $318.2 \mathrm{~K}$ & -8.463 & & & \\
\hline $328.2 \mathrm{~K}$ & -9.298 & & & \\
\hline
\end{tabular}

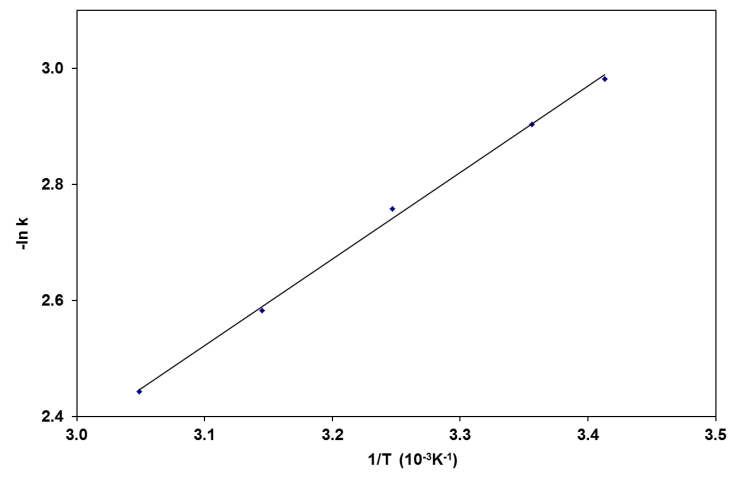

Figure 6. Relationship between -ln k and 1/T.

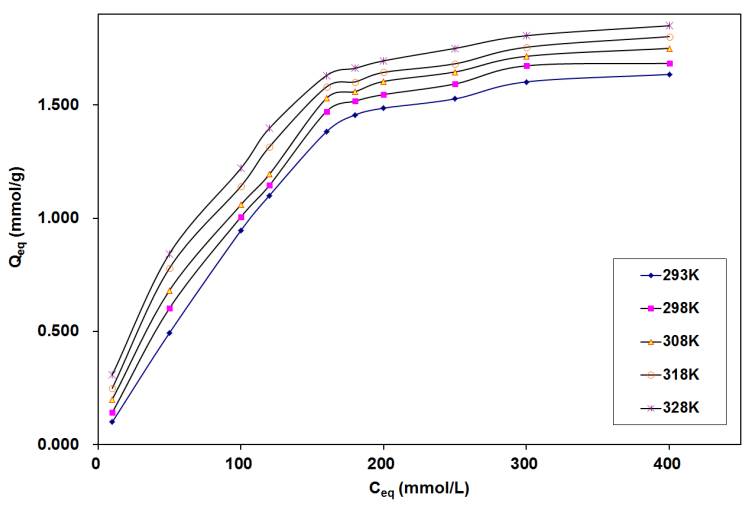

Figure 7. Adsorption capacity of $\mathrm{Co}^{2+}$ at different temperatures.

where $C_{\mathrm{eq}}$ and $\mathrm{Q}_{\mathrm{eq}}$ are the equilibrium concentration of metal ions (mmol/L) and the adsorption capacity (mmol/g), respectively; $\mathrm{Q}_{\mathrm{m}}$ is adsorption capacity $(\mathrm{mmol} / \mathrm{g}) ; \mathrm{K}_{\mathrm{L}}$ is the equilibrium constant $(\mathrm{L} / \mathrm{mmol})$.

The experiment data (Figure 8) are fitted using Langmuir equation and the corresponding adsorption parameters along with regression coefficients are listed (Table 2). From Figure 8, we can see that the adsorption of $\mathrm{Co}^{2+}$ onto the $\mathrm{CS} / \mathrm{HA}$ can be fitted well according to the Langmuir model. Langmuir model assumes that the adsorbent surface has adsorption sites with identical energy and each adsorbed molecule takes part in a single site [28], thus following a monolayer adsorption model. From Table 2, we can see that the $\mathrm{Q}_{\mathrm{m}}$ and $\mathrm{K}_{\mathrm{L}}$ increase with increasing temperature. The result shows that the adsorption of $\mathrm{Co}^{2+}$ onto the CS/HA is an endothermic process.

The relationship between $\mathrm{K}_{\mathrm{L}}$ and $\mathrm{T}$ can be obtained from the Van't Hoff equation [29,30]. It is listed below.

$\ln \mathrm{K}_{\mathrm{L}}=-\Delta \mathrm{H}^{\ominus} / \mathrm{RT}+\Delta \mathrm{S}^{\ominus} / \mathrm{R}$ where $\Delta \mathrm{H}^{\ominus}(\mathrm{J} / \mathrm{mol})$ and $\left.\Delta \mathrm{S}^{\ominus} \mathrm{J} / \mathrm{mol} . \mathrm{K}\right)$ are the enthalpy and the entropy of the adsorption, respectively; $\mathrm{R}$ is the ideal gas constant; $\mathrm{T}(\mathrm{K})$ is temperature.

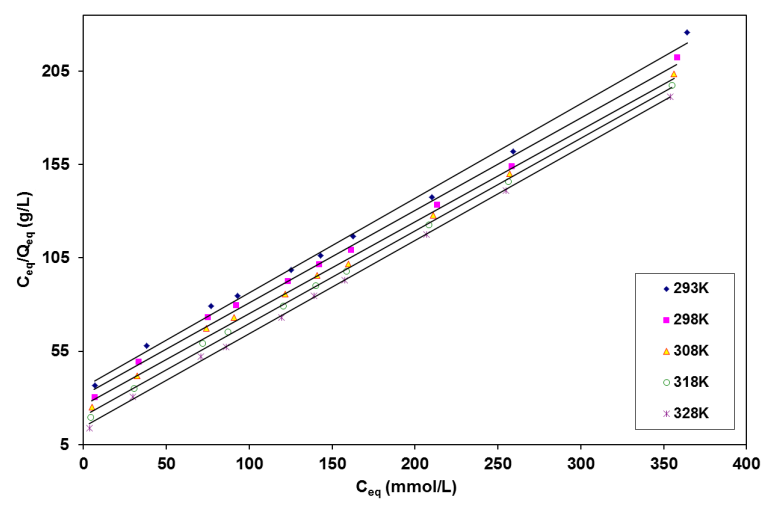

Figure 8. Relationship between $\mathrm{C}_{\text {eq }} / \mathrm{Q}_{\mathrm{eq}}$ and $\mathrm{C}_{\mathrm{eq}}$.

As is shown, $\ln \mathrm{K}_{\mathrm{L}}$ has a linear relationship with $1 / \mathrm{T}$ with an $r^{2}$ value of 0.9888 (Figure 9). The slope and intercept are $-\Delta H^{\ominus} /$ $\mathrm{R}$ and $\Delta S^{\ominus} / \mathrm{R}$, respectively. And $\Delta H^{\ominus}$ and $\Delta S^{\ominus}$ are determined to be $18.09 \mathrm{~kJ} / \mathrm{mol}$ and $83.50 \mathrm{~J} / \mathrm{mol} \cdot \mathrm{K}$, respectively. The results of $\Delta G^{\ominus}$ are listed in Table 3.

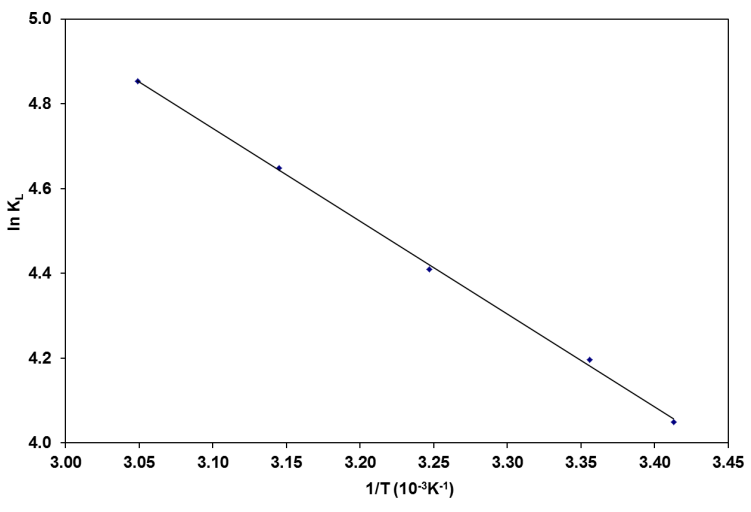

Figure 9. Relationship between $\operatorname{lnk}_{\mathrm{L}}$ and 1/T.

The value of $\Delta H^{\ominus}$ is positive, which indicates that, the adsorption of $\mathrm{Co}^{2+}$ onto the $\mathrm{CS} / \mathrm{HA}$ is an endothermic process. The value of $\Delta S^{\ominus}$ is positive, which also indicated that the process is caused by the increased randomness during the adsorption of $\mathrm{Co}^{2+}$ [16]. The value of $\Delta G^{\theta}$ is negative at all of the five temperatures. The $\Delta G^{\theta}$ decreases with the increase of temperature. It suggests that the adsorption of $\mathrm{Co}^{2+}$ onto the $\mathrm{CS} / \mathrm{HA}$ is a spontaneous progress. The spontaneous degree becomes greater with the increase of temperature. Therefore, 
increasing temperature is beneficial to the adsorption procedure [31].

\section{Conclusion}

The chitosan-hydroxyapatite composite material is prepared using chitosan, lime nitrate tetra-hydrate and potassium di-hydrogen phosphate as raw material by in situ composite method. The influences of adsorption time, temperature, initial cobalt concentration and $\mathrm{pH}$ on the adsorption kinetic and thermodynamic of $\mathrm{Co}^{2+}$ are studied. Our results show that the optimum time is $480 \mathrm{~min}$ and the optimum $\mathrm{pH}$ is between 5 and 7 . The adsorption kinetics of $\mathrm{Co}^{2+}$ on the CS/HA is found to follow the pseudo-second-order kinetic model, and the apparent adsorption activation energy is measured to be $10.73 \mathrm{~kJ} / \mathrm{mol}$. The Langmuir adsorption model fits well with the experimental data. The adsorption thermodynamic parameters such as $\Delta H^{\ominus}, \Delta S^{\ominus}$, and $\Delta \mathrm{G}^{\ominus}$, are obtained, which indicate that the adsorption process is spontaneous and endothermic.

\section{Acknowledgements}

This work was supported by the National Natural Science Foundation of China (Project No: 61001051), the Natural Science Foundation of Hebei Province (Project No: F2011201102).

\section{References}

[1]. Ouyang, H. F. J. Chin. Feed. 1999, 15, 28-29.

[2]. Li, Y. D.; Yuan, Z. H.; Li, H. Q. J. Bull. Chin. Agric. Sci. 2007, 23, 458-461.

[3]. Huang, W. H.; Su, H. D. Trans. Shenyang Ligong Univ. 2008, 27, 87-90.

[4]. Fonseca, M. G.; Oliveira, M. M.; Arakaki, L. N. H.; Espinola, J. G. P.; Airoldi, C. J. Colloid Interf. Sci. 2005, 285, 50-55.

[5]. Erdem, E.; Karapinar, N.; Donat, R. J. Colloid Interf. Sci. 2004, 280, $309-$ 314.

[6]. Kara, M.; Yuzer, H.; Sabah, E.; Celik, M. S. Water Res. 2003, 37, 224232.

[7]. Yavuz, O.; Altunkaynak, Y.; Guzel, F. Water Res. 2003, 37, 948-952.

[8]. Ma, Z. G.; Liu, S. W.; Zhang, H. L.; Liu, P.; Di, N. Int. J. Chem. 2011, 3, 116-120.

[9]. Ma, Z. G.; Di, N.; Zhang, F.; Gu, P. P.; Liu, S. W.; Liu, P. Int J. Chem. 2011, 3, 18-23.

[10]. Li, Q.; Xi, D. L. J. Environ. Prot. Chem. Ind. 2005, 25, 350-352.

[11]. Yang, M. P.; Li, G. B. J. Mater. Prot. 2003, 36, 37-38.

[12]. Chu K. H. J. Hazard. Mater. 2002, 90, 77-95.

[13]. Burke, A.; Yilmaz, E.; Hasirci, N. J. Appl. Polym. Sci. 2002, 84, 11851192.

[14]. Dhakal, R. P.; Inoue, K.; Yoshizuka, K. Solvent Extr. Ion Exc. 2005, 23, 204-208.

[15]. Liu, H. D.; Li, F. Z.; Zhao, X. Chin. J. Process Eng. 2008, 8, 42-47.

[16]. Li, B. Q.; Hu, Q. L.; Wang, M.; Shen, J. C. Chem. J. Chin. Univ. 2004, 10, 1949-1952.

[17]. Chiou, M. S.; Hsing, Y. L. J. Hazard. Mater. 2002, 93, 233-248.

[18]. Qu, R. J.; Sun, C. M.; Wang, M. H. Hydrometallurgy 2009, 100, 65-71.

[19]. Wan-Ngah, W. S.; Ghani, S. A.; Kamari, A. Biores. Technol. 2005, 96, 443-450.

[20]. Smiciklas, I.; Dimovic, I; Plecas, I.; Mitric, M. Water Res. 2006, 40, 2267-2274.

[21]. Huang, Y. R.; Li, Z. J.; Wang, H. F.; Miao, Z. C.; Liu, J. G. Appl. Chem. 2009, 38, 1093-1097.

[22]. Sun, X. L.; Zeng, Q. X.; Feng, C. G. Acta. Phys. Chim. Sin. 2009, 25, 19511957.

[23]. Mohan, D.; Pittman, J. C. U. J. Hazard. Mater. 2006, 137, 762-811.

[24]. Sag, Y.; Aktay, Y. Biochem. Eng. J. 2002, 12, 143-153.

[25]. Wan-Ngah, W. S.; Ab-Ghani, S.; Kamari, A. Bioresource Technol. 2005, 96, 443-450.

[26]. Huang, J. H. J. The Light Text. Ind. Fujian. 2005, 7, 15-17.

[27]. Langmuir, I. J. Am. Chem. Soc. 1916, 38, 2221-2295.

[28]. Vasconcelos, H. L.; Favere, V. T.; Goncalves, N. S.; Laranjeira, C. M. React. Funct. Polym. 2007, 67, 1052-1060.

[29]. Atia A.; Donia A.M.; El-Boraey H.A. Sep. Purif. Technol. 2006, 48, 281287.

[30]. Ozcan, A.; Ozcan, A. S.; Tunali, S.; Akar, T.; Kiran, I. J. Hazard. Mater. 2005, 124, 200-208.

[31]. Tang, J. Y.; Li, X.; Ying, H. J. J. Nanjing Univ. Technol. 2006, 28, 79-83. 